\title{
Atypical rabies with MRI findings: clue to the diagnosis
}

\author{
Arvind Kumar Vaish, Nirdesh Jain, Lokesh Kumar Gupta, Sudhir Kumar Verma \\ Department of Internal medicine, CSM Medical University, Lucknow, India
}

Correspondence to Professor Arvind Kumar Vaish, vaish12@rediffmail.com

\begin{abstract}
Summary
Rabies is known for most as a fatal infectious disease, mainly transmitted to both humans and animals through bites by rabid animals. In its classical form, rabies is well recognised, but when it presents atypically in paralytic form, it may become difficult to distinguish from Guillain-Barré syndrome (GBS) or myelitis, particularly where history is not forthcoming or concealed. The authors report here an atypical case of paralytic rabies presenting with descending paralysis followed by furious form where clue to suspicion was MRI findings. Imaging in rabies is seldom done. MRI findings of rabies encephalitis are well known, but in myelitis these need to be further characterised. The authors present MRI findings in a confirmed case of rabies myelitis. The differential diagnosis of the imaging findings as well as the role and the relevance of imaging in the diagnosis of this disease are discussed.
\end{abstract}

\section{BACKGROUND}

Rabies continues to be a serious health hazard in several parts of the world including India, where it is endemic, and is responsible for 20565 deaths per year. ${ }^{1}$ Rabies can manifest itself in two forms: classic encephalitic (furious) rabies and paralytic (dumb) rabies. Both forms are progressive and generally lead to death. ${ }^{2}$ Paralytic rabies accounts for $20 \%$ of rabies. Hydrophobia and aerophobia are present only in half of these patients. It is possible that many cases are misdiagnosed because the disease is not often recognised in classical form, more so when history of an animal bite is not forthcoming. These cases are sometimes clinically indistinguishable from Guillain-Barré syndrome (GBS). ${ }^{3}$ More important is the lack of clear documentation of spinal abnormalities on imaging in cases of paralytic human rabies. When MR imaging of the spine suggests myelitis, paralytic rabies should be a differential diagnosis. In a patient whose condition progresses from flaccid paralysis with myelitis evident on MR images of the spine to both paralysis and encephalitis, rabies should be strongly considered.

\section{CASE PRESENTATION}

A 25-year-old male was admitted to emergency unit for weakness of left upper limb followed by weakness of right upper limb over a period of 2 days, accompanied with fever for 8 days. History of numbness, paresthesias and bladder bowel involvement were absent. On examination, he was febrile and higher mental functions were normal (Mini-Mental Score Examination $=25$ ). There were no signs of meningeal irritation. All cranial nerves were intact. Both upper limbs were hypotonic, areflexic, and power was $2 / 5$ on Medical Research Council scale. Lower limbs were normal on initial examination and plantars were flexor bilaterally. There were no definite findings on sensory examination. He also had retention of urine. Rest of systemic examination did not reveal any abnormality.
Over a hospital stay of 3 days, the patient's consciousness deteriorated (MMSE = 18). He developed weakness of both lower limbs on day 2 which progressed to involve respiratory muscles over the next $24 \mathrm{~h}$. Neurological examination then revealed a power of $1 / 5$ and $2 / 5$ in upper and lower limbs respectively. Weakness was accompanied with hypotonia, areflexia and non-elicitable plantar reflexes. He also developed dysphagia, dysphonia and breathlessness. Ventilatory support was provided to the patient. History of being bitten by dog over left forearm one month ago for which he had also received two dose of rabies vaccine was given by his relatives on day 5 . Eventually, the patient expired on the same day. Postmortem examination was not allowed by his relatives.

\section{INVESTIGATIONS}

Laboratory investigations showed a slightly raised total leucocytes count and normal platelet count $\left(13000 / \mathrm{mm}^{3}\right.$ and $1.7 \times 10^{5} / \mathrm{mm}^{3}$, respectively). Blood sugars and serum electrolytes were normal. Viral hepatitis markers and test for HIV were negative. Cerebrospinal fluid (CSF) examination showed protein $28.3 \mathrm{mg} / \mathrm{dl}$, cells 45 per cubic $\mathrm{mm}$ (20\% polymorphs and $80 \%$ lymphocytes) and sugar content of $74.9 \mathrm{mg} / \mathrm{dl}$ with corresponding blood sugar level of $130.3 \mathrm{mg} / \mathrm{dl}$. Fundus examination and CT scan of brain were normal. MRI, T2W image of cervico-dorsal region showed hyperintense signal in central gray matter, extending cranially to involve medulla with expansion of cervical cord suggestive of myelitis (figure 1A-D).

Later on, rabies virus antibodies were detected in stored sample of CSF.

\section{DIFFERENTIAL DIAGNOSIS}

- Guillain-Barré syndrome

- Myelitis. 


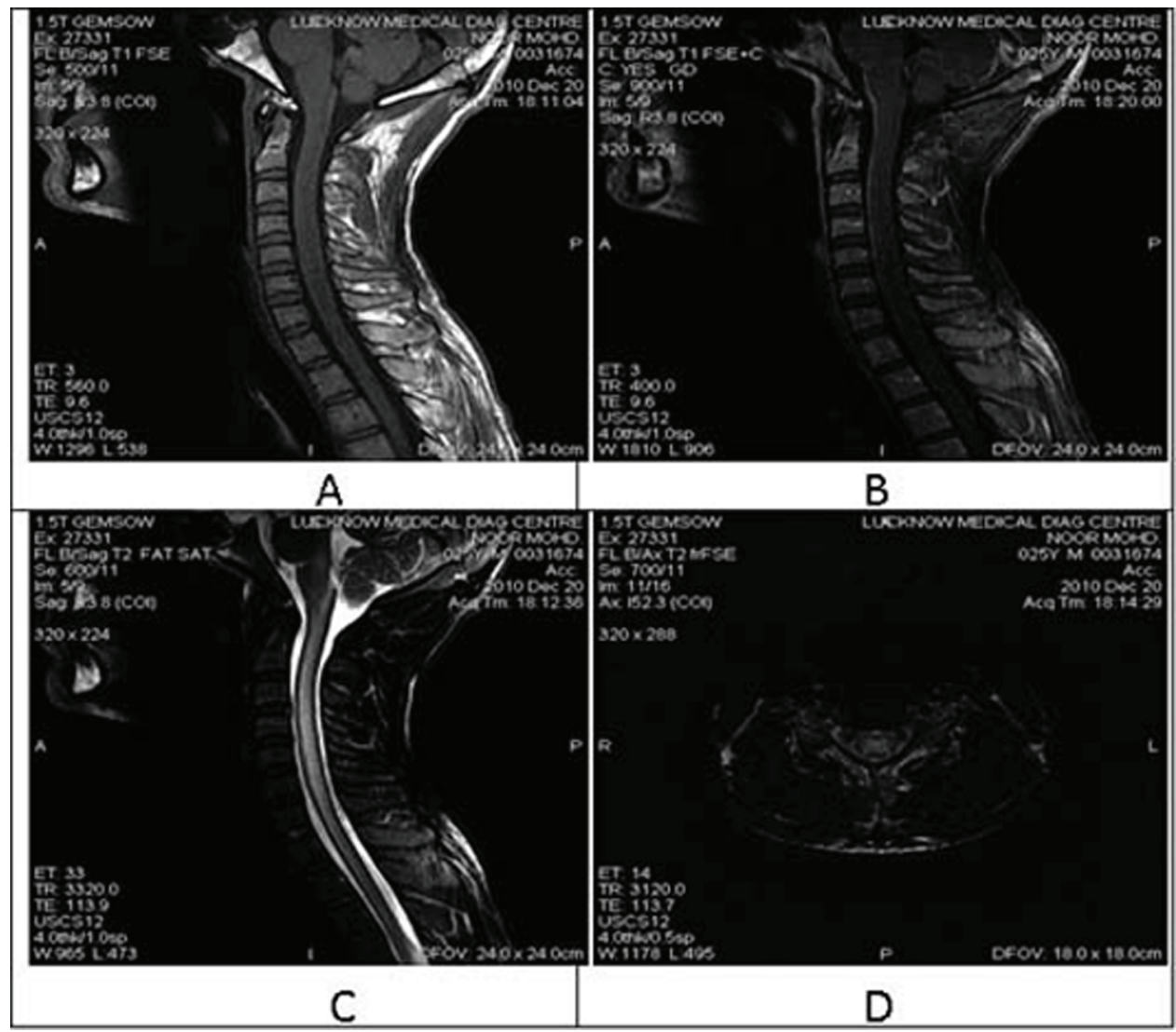

Figure 1 MRI (1.5 Tesla) cervico-dorsal saggital view shows isointense to hypointense signal in T1W image which does not enhance on contrast study $(A, B)$. Saggital T2W image shows hyperintense signal extending from medulla to sixth dorsal segment with expansion of cord in cervical region (C). Axial T2W Fat suppression image of cervical cord shows hyperintense signal involving grey matter more on left side with mild cord swelling (D).

\section{TREATMENT}

Supportive treatment and later on ventilatory support was given to the patient.

\section{OUTCOME AND FOLLOW-UP}

Patient expired on day 5.

\section{DISCUSSION}

The patient described herein presented as paralytic rabies, because classic signs of rabies, such as autonomic dysfunction and phobic spasm, were not obvious. ${ }^{4} \mathrm{He}$ also had relatively spared consciousness initially. Patient had descending paralysis. However, ascending or descending weakness can be found in paralytic rabies. ${ }^{5}$ Paralytic rabies can pose great diagnostic challenge. These cases resemble radiculomyelitis. Paralytic rabies usually occurs in people bitten by rabid animal who have received incomplete vaccination and secondary prophylaxis as happened in this case. There is no characteristic findings which can help to distinguish paralytic rabies from GBS or myelitis except for the rapidity with which the illness progresses and proves fatal in 5-10 days in rabies. In our case, the rapid progression together with later development of encephalitic features, later history of dog bite and incomplete vaccination helped us to arrive at the correct diagnosis.
It is not known how much neuroimaging studies would be helpful in rabies. As the disease is uniformly fatal, often neuroimaging is not done. In few studies, neuroimaging finding on CT/MRI have been mainly studied in classical furious rabies. ${ }^{6-8}$ In paralytic rabies, the neuroimaging findings are very few and inconsistent. Furthermore, these have been done 7-8 years back when CT/MRI were at its inception. Now, however, considerable advances have been made in these imaging modalities. In our case, MRI of the spinal cord revealed increased signal intensity involving mainly the central part of the spinal cord on T2W image with expansion of the cord from medulla to C-6 spinal segment. On transverse section, there was mainly involvement of the grey matter of the spinal cord (like poliomyelitis) with relative sparing of the white matter. These findings are consistent with clinical presentation. The predominant involvement of the neurons and grey matter is also consistent with the diagnosis of rabies. ${ }^{9} 10$ Thus MRI finding can give important clue to diagnosis of rabies. Furthermore, they may also help to differentiate paralytic rabies from acute disseminated encephalomyelitis (post-vaccinial), where there is predominant white matter involvement of the cord and also from GBS. ${ }^{3}$ Neuroimaging may therefore also provide important prognostic information. 


\section{BMJ Case Reports}

\section{Learning points}

- Human paralytic rabies should always be suspected regardless of history of animal exposure where clinical findings are not typical for acute transverse myelitis and GBS.

- Neuroimaging findings may support your diagnosis; however, there have been few reports documenting features of rabies myelitis, and, therefore, further evidence are warranted to make them characteristic.

- Prompt diagnosis of rabies can enable rapid case investigation, institution of appropriate measures and, most importantly, infection-control measures.

\section{Competing interests None.}

Patient consent Obtained.

\section{REFERENCES}

1. Deshmukh RA. Rabies. Pune: Yogaksema Department of Virology, Haffkine Institute 2004.

2. Hemachudha T, Laothamatas J, Rupprecht CE. Human rabies: a disease of complex neuropathogenetic mechanisms and diagnostic challenges. Lancet Neurol 2002;1:101-9.

3. Mani J, Reddy BC, Borgohain R, et al. Magnetic resonance imaging in rabies. Postgrad Med J 2003;79:352-4.

4. Hemachudha T, Wacharapluesadee S, Mitrabhakdi E, et al. Pathophysiology of human paralytic rabies. J Neurovirol 2005;11:93-100.

5. Laothamatas J, Wacharapluesadee S, Lumlertdacha B, et al. Furious and paralytic rabies of canine origin: neuroimaging with virological and cytokine studies. J Neurovirol 2008;14:119-29.

6. Sing TM, Soo MY. Imaging findings in rabies. Australas Radiol 1996:40:338-41.

7. Murthy JM. MRI in acute disseminated encephalomyelitis following Semple antirabies vaccine. Neuroradiology 1998;40:420-3.

8. Rao AS, Varma DR, Rao MVC, et al. Magnetic resonance imaging in rabies encephalitis. Indian J Radiol Imaging 2009;19:301-4.

9. Centers for Disease Control and Prevention. Human rabies: California, 1994. MMWR Morb Mortal Wkly Rep 1994;43:455-8.

10. Centers for Disease Control and Prevention. Human rabies: California, Georgia, Minnesota, New York, and Wisconsin, 2000. MMWR Morb Mortal Wkly Rep 2000;49:1111-15.

This pdf has been created automatically from the final edited text and images.

Copyright 2011 BMJ Publishing Group. All rights reserved. For permission to reuse any of this content visit

http://group.bmj.com/group/rights-licensing/permissions.

BMJ Case Report Fellows may re-use this article for personal use and teaching without any further permission.

Please cite this article as follows (you will need to access the article online to obtain the date of publication).

Vaish AK, Jain N, Gupta LK, Verma SK. Atypical rabies with MRI findings: clue to the diagnosis. BMJ Case Reports 2011;10.1136/bcr.05.2011.4234, date of publication

Become a Fellow of BMJ Case Reports today and you can:

- Submit as many cases as you like

Enjoy fast sympathetic peer review and rapid publication of accepted articles

- Access all the published articles

- Re-use any of the published material for personal use and teaching without further permission

For information on Institutional Fellowships contact consortiasales@bmjgroup.com

Visit casereports.bmj.com for more articles like this and to become a Fellow 